\title{
Path dependence and novelties in Russian innovation
}

Irina Dezhina ${ }^{1 *}$ and Henry Etzkowitz ${ }^{2}$

\author{
* Correspondence: \\ i.dezhina@skoltech.ru \\ ${ }^{1}$ Group on Science and Industrial \\ Policy, Skolkovo Institute of Science \\ and Technology, Nobelya str., 3, \\ Moscow 143026, Russia \\ Full list of author information is \\ available at the end of the article
}

\section{Introduction}

Russia has a relatively consistent innovation policy, despite significant changes in the political sphere, from the break-up of the Soviet Union to the re-centralizing of political control during the Putin era. Government was and is the central actor in the innovation system; this system continues to be hierarchical. A hierarchical innovation leadership format well precedes the Soviet Union and may be traced back to innovation modernizers like Peter the Great who established the key institutions of vertical innovation. Nevertheless, a minor key of horizontal triple helix interactions, exemplified by several universities that have explicitly taken on an entrepreneurial mission, has emerged as a complement to centralization, the persisting path dependent major key of Russian Innovation policy and practice.

The Russian science and technology system, after the breakup of the Soviet Union, has experienced an ongoing attempt at reform. This effort is characterized by adoption of models from abroad, for example, universities that combine multiple missions of teaching and research as well as innovation and entrepreneurship. Previously, universities were largely confined to education in relative isolation from research institutes. Although this system persists, its importance is reduced, given the increasing significance of universities as research providers.

Although instituted top down, complemented with research funding agencies, this reform introduces a horizontal and even bottom-up element into Russian innovation practice as universities are more or less expected to find their own way in implementing this reform. Indeed, the government's sponsoring of university metrics may be seen as an effort, to influence and track these developments, without trying to exercise strict bureaucratic controls.

Some horizontal linkages develop in selected innovative clusters (between large and small companies), in technology platforms that initiate new joint R\&D projects. Aside from that, the current system becomes less disconnected as institutes become more involved in teaching, and teaching universities do research and some subset become entrepreneurial, spinning off start-ups, with government seeming to encourage this trend. But centralizing ambitions may be beyond the reach of attainment. In regions where administration cares about innovative development, external conditions for $R \& D$ and innovation may be fixed to some extent. Regional governments for that purpose use tax mechanisms, improve customs service, and invest in infrastructure. 
Regional universities in such places are oriented towards closer cooperation with local industry both in research and training of new workforce.

\section{Government's innovation role}

The role of government is important in any country, even in the well horizontally developed systems, but government functions are different there. Government should be regulator, not dictator. In between hands-off regulator and dictator is a Public Entrepreneur model characteristic, for example of the USA, going well beyond regulation, but yet not attempting to monopolize direction. Government plays a variety of roles from providing research funds to academia in areas that government has an interest in innovation that helps it fulfill its explicit functions to more direct formats in which government agencies formulate and carry out their own R\&D projects.

The quintessential US strategy has been for government to incentivize and encourage university and industry to work together with government on innovation projects. The initiative for these projects can come from various sources; thus, the Genome project emerged from the Energy Department and National Institutes of Health from within government during the 1990s, the Sematech initiative from the semiconductor industry in response to Japanese competition during the 1980s, and the Manhattan project from academia during the Second World War. ${ }^{1}$

In Russia, the Soviet legacy when everything is under government control continues to be very strong. For example, in a draft strategy for scientific-technological development of the Russian Federation till the year 2035, one of the suggestions is to make government responsible for all technology transfer in the country. This is only at the level of intention, but the trend towards centralization is evident. Institutes for development help with technology transfer, and each of them has its own niche. But this kind of mentality may be also found at the level of institutional leadership: "old generations" of directors dream about reincarnation of "branch science" and system of "vnedreniya" (deployment) when novelty moves from R\&D to production chain under government push. This is now more at the level of mentality, not actual possibility.

Today in Russia, government continues to be the major source of financing for R\&D and the input from business is decreasing. The share of federal government is about $70 \%$ in the total expenditures on R\&D, and business enterprise sector invests about 25-27\%. Government support grows more rapidly than financing from companies. Official statistics does not allow us to define companies from which branches invest more. However, indirectly it may be said that these are big state companies in resource extracting industries: they provide up to $80 \%$ of total financing for R\&D.

Other sources are also decreasing. In particular, the result of government policy regarding "foreign agents" and "unwelcomed" organization is in the decrease of foreign financing for R\&D. The majority of foreign agents are foundations of US origin and private foundations (like Dynasty Fund of Dmitry Zimin).

At the same time, government realizes the problem of insufficient results in S\&T and is searching for instruments to improve the situation. Usually, the source of ideas is foreign experience. Foreign experience is carefully and regularly studied by universities, research organizations, and academy institutes by request of federal agencies responsible for the development in S\&T (like Ministry of Education and Science, Ministry of Economic Development, and Ministry of Industry and Trade). 
At the present time, the new framework idea of "grand challenges" is introduced to the scientific community. It is based on the assumption that grand challenges shape the choice of technological priorities that the government should support.

Over the last 25 years, many new measures were introduced, including support of universities, privatization of former branch R\&D institutes, reform of the Russian Academy of Sciences, creation of innovative infrastructure, establishment of science foundations and institutes for development, and start of prestigious infrastructural projects, such as Skolkovo, Innopolis, and Moscow State University (MSU) Technological Valley. A separate set of horizontal instruments was established in order to stimulate linkages in innovation system: technological platforms, innovative clusters, encouraging mobility, project consortia between research institutes (universities) and companies, and others.

The outcome of all that activity is less impressive than the list of implemented measures. What went wrong? To the date, the answer may be quality and mentality of government regulation, within and outside of the S\&T area.

\section{University's innovation role}

Universities in Russia were mainly teaching institutes under the regulation of the law "About Education in RF." At the present time, they continue to be mainly teaching institutes but the role of research and innovation has visibly increased. There is a growing share of research conducted in universities and increasing number of personnel involved in R\&D. Publication record is also improving. Universities receive big support from the government, especially the leading group of 20+ universities that enjoy generous financial support. Aside from the appreciation of research and innovation, universities become more aware of the "entrepreneurial university" concept. The ideas of such type also come from abroad, sometimes in an exaggerated form. For example, in the mid-2000, a popular idea among universities was that their major income may be from technology commercialization, such as selling patents and licenses. This was the result of the misunderstanding of how best American universities work.

At the same time, government policy towards universities may be characterized as "picking winners," which leads to segregation among higher educational institutes. Those who are not in a leading group have to be really innovative for the sake of survival. So the change is under way, whether more or less resources. And it continues to be a question which is the most effective driver of innovation. The US example shows that public universities, including leaders like Berkeley, are under similar extreme financial pressures, with reduction from 25 to $9 \%$ of state support in the past decade. They look for donors, which is not a possibility for Russia. There are too few universities with endowments in Russia, and this culture of giving is not developed neither mentally nor economically. Donors do not have any tax privileges when they give out money for charitable purposes.

Important government push towards better research in universities is based on a confusing stimulus to be higher in international ratings. In a way it is now an international phenomenon. Ratings may be good if they are based on fair metrics. However, at the present time, the role of bibliometric and quantitative indicators is overstated. A more variegated metrics, including start-up creation and growth, contribution to regional 
economy and society, and a balance between quantitative and qualitative indicators, are required.

Influence of government course is visible through the changing focus of university research: growing expenditures on defense $R \& D$ make universities move towards this type of activities. Some universities are particularly bright examples at this respect-TUSUR (Tomsk) - as well as a number of technical universities in Moscow. In the TUSUR case, algorithmic expertise became the basis of firms, some of whose aim was to improve the technologies of older mechanical industries. In other instances, software with advanced capabilities was developed and marketed as start-up firms in Silicon Valley.

The entrepreneurial direction at TUSUR, founded as a highly specialized research institute that had developed teaching programs, emerged as a response to the reduction of government funding for the University's role in the space and military programs. More recently, as government funding for military research increased, TUSUR was drawn back into its former role. TUSUR's entrepreneurial role has been picked up by Tomsk Polytechnic, the university that TUSUR originally spun-off from at the height of success of the Soviet space program. The case illustrates the transition of academic institutions to a more differentiated role in Russian society, moving away from the single purpose mode of the Soviet era.

\section{Industry's innovation role}

Industry is also changing though by formal indicators, the change is the least visible. Big state companies are not very innovative and not willing to invest much in R\&D. Their technological development is based, to a considerable extent, on import of equipment. Sanctions are stimulus for innovations in a limited number of areas, like food production, textile industry, or any other industries, that may easily start the production of own components for products. Survey conducted by the Russian Venture company in 2015 among 196 respondents from government, business, and science has demonstrated that almost two thirds of respondents think that sanctions hamper innovations.

In many cases, sanctions have led to the change in the country-supplier of new technology. Small innovative companies, though supported through various government institutes for development, suffer from unfavorable economic environment and lack of connections with big companies (lack of consumers). On a positive side, there is growing number of successfully developing medium-sized companies. The largest share of such companies, according to the 2016 survey conducted by the Higher School of Economics by the order of Skolkovo Institute of Science and Technology, is in instrument making, electronics, IT, and pharmaceuticals. Most of such companies were established at the beginning of 1990s by engineers or specialists in hard sciences. Medium-sized company is defined as the one with the annual income between 50 million and up to 10 billion RUR. They invest in R\&D and innovation, find new customers and market niches, and demonstrate up to $15 \%$ of annual income growth. The number of these companies is not large, but they give a hope that high-tech business may develop in Russia. Such companies usually have well-established linkages with universities though universities are mainly seen by them as a source of new employees, and not partners for R\&D. Such companies prefer to conduct in-house R\&D. They take part in many government programs, including the ones related to venture 
funds and various grants, but many of them say that government financial support is important but not crucial.

\section{Civil society's innovation role}

Society is an important part of the whole innovation system. Society may be seen in two projections. First, society is a taxpayer, the one who should understand the value of science and support it. In Russia, respect to a researcher engineer is rather low-it was not the case in the Soviet Union where salary of teaching staff and researchers was higher than average and academic freedom put them in a special privileged working conditions. The change has occurred partially because of comparatively low income of such specialists. Additionally, popularization of science and technologies in Russia was during the last 25 years at a very modest scale. Citizens do not understand what science gives them; instead in newspapers and magazines, one may read about scandals and rumors around institutes for development (ROSNANO, Skolkovo, MSU Technological Valley), or scandals around reform of RAS, or about confrontation between academy institutes and universities in their fight for federal money.

Second, society may be seen as citizen science, reflections of which are crowdsourcing, Wikipedia, and other novelties from recent times. In another words, society in this case is a source of ideas. Citizen science, in turn, usually may prosper only in civil society. Civil society in Russia is underdeveloped. Indeed, the very term now has a rather negative connotation since it was brought to the country by foreign (mostly American) foundations. Building civil society was in their agenda, and some elements of civil society do exist in Russia. For example, the Society of Scientific Researchers which is a union of scientists, researchers, and even scientific journalists who are interested in problems around the scientific complex and are ready to raise their voice in support (or against) new policy measures. But overall, the attempt of foreigners to expand civil society failed. Nevertheless, an indigenous civil society tradition expressed in samizdat and underground artistic movements during the Soviet era and in the attempt to build an independent media during the post-Soviet era, persists.

Having such composition and characteristics of actors, where is Russia going now? The government tries to set a new agenda and to find novel ways of setting priorities in S\&T. First, it is National Technology Initiative, announced by the President in 2014. The idea is to move from demand to supply-from potential market niches that could Russia occupy to the search for necessary resources that country needs in order to become one of technological leaders. The approach is complex and deals not only with science and technology but also with the system of education (starting from kinder gardens), societal views, and revision of conditions, external to S\&T. Second, the Russian government is going to set new goals and instruments specifically in science and technology, by developing Strategy for scientific-technological development till the year 2035. This document should formulate "big goal" for scientific and technological complex. So far, in NationalTechnology Initiative, ten promising net markets are identified, including aero, auto, marinet, finnet, neuronet, safenet, technet, and some others. In order to enter any of these markets, new technologies should be developed in such areas as new materials, Big Data, and photonics. 
It is not clear yet what will be the balance between reliance on natural advantages that the country possesses (like good math education and special schools for gifted children that allow Russia to be among world winners in various math and IT contests) and needs to develop certain areas and even branches (like advanced manufacturing or agricultural sector).

Some initiatives may be restructured according to "grand challenges" - for example, Skoltech may build more capacity based on national technological priorities (photonics, neurotechnologies, advanced manufacturing, IT), as well as leading universities may reconsider their priority subject areas in teaching courses. Skolkovo Fund priorities shifted from a mix of old and new topics to more advanced, more highly focused choices. At the same time, formal structure of "clusters" in Skolkovo Fund stays the same. Finally, it should be underlined that external environment to science and technological development is playing an important role in Russia. Tax and customs regulations, visa requirements, regulation of mobility, etc., all these mechanisms should be enhanced so that Russia could transform itself into horizontally developed triple helix.

\section{The "Russian Collection" in the Triple Helix journal}

The issue presents a "Russian collection" of papers. It includes five papers which are related to the Triple Helix theory and model. However, aside from that, this selection of papers brings the light to the nature and specificity of linkages among various actors in innovation system. The problem of lacking linkages is especially sharp for Russia. It has been discussed for years but still remains far from being solved. What is the reason? The Triple Helix model is not working in Russia, and the linkages are mostly vertical, not horizontal-the system is centered on the State. Federal financing for $R \& D$ is overwhelming, and most of organizations dealing with science and innovations are government-owned or government-regulated. This creates double helices of relationships-"government-industry," "government-universities," and "governmentresearch institutes." In these pairs, government plays a leading role. The pair "scienceindustry" is also present but it is not strong. Its strengthening is an important task for Russia and that is why three out of five papers are exploring different aspects of these relationships between science and business, mechanisms of knowledge transfer through various mechanisms, including circulation of workforce, joint work on shared equipment, establishment of startups by universities, and some others.

Two remaining papers bring readers to the next level, by looking at the processes on the whole-country scale and in comparative perspective with other countries which are overcoming similar formidable obstacles. Russia is compared with China (Balzer, Askonas) which has a much longer history of reforms in science (75 years against 25 in Russia). Another macro-case is Armenia (Inzelt), a country that was a part of the Soviet Union and thus inherited many features of the system that are common with Russia. There are no direct comparisons between Russia and Armenia; however, "Armenian case" helps to understand Russia's place and stage in the process of reforms.

Balzer and Askonas underline that in both Russia and China, the role of the government in the Triple Helix is overstated and studies often focus on the potential for the state to foster the creative process. The authors think that China is much more successful than Russia in transforming its innovation system, not taking into consideration that China started reforms much earlier than Russia and thus in Russia, in 50 years, the 
picture may be similar to the Chinese one. For example, China started to support a selected group of "elite" universities in 1956, Russia-in 2006. Therefore, it would be interesting to see where Chinese universities were in the 1980s of the XX century.

At the same time, observations regarding Russia and government policy are very sharp and fare-authors state that Russian leaders have little patience and would like to see fast results. Indeed, during the post-Soviet years, Russian government has introduced a lot of measures aimed at strengthening linkages in the innovation system. Many of these were borrowed from foreign (Western) experience. However, most of measures did not last long; their implementation was poorly monitored and thus instruments were not working in the same way as abroad. This "lack of patience" along with overall economic regulation made Russia less successful than China. This shows that not only "effective mechanisms" should be applied but they have to be suited to the right political context. And the authors make the politics-related conclusion: "Russia under Vladimir Putin remains excessively focused on control and promoting the state sector. There has been far less learning."

Political theme is continued through the analysis of Armenia-a small part of Soviet science empire with strong fundamental science. Inzelt states that the way of thinking in Armenia still corresponds to a science-push model. In addition to that, the information on the involvement of business in support of technological innovations is very scarce and limited. Thus, such a general indicator as Business Expenditure on R\&D is unavailable for Armenia. There is also very limited information on the regulation of public-private partnerships in this country, and incentives for cost-sharing. There are no government programs for spin-offs as well. Overall, the business sector in Armenia is not well developed, and the scarcity of innovative companies is a serious handicap for industry-science collaborations. In this respect, Russia has moved further in promoting innovation culture within its business sector. Therefore, Armenia presents the case with very weak science-industry linkages.

Another noticeable aspect in comparative perspective is the process of reforms in the Academies. Both Russia and Armenia have state Academies which for years were more important generators of knowledge than universities. Armenian government introduced a new law about its Academy in 2011-2 years earlier than Russia. Armenia faces the same problems with the scientific workforce-aging, lack of interest, and capability for innovation. The transformation process is painful and Russia is not alone in slow pace of reforms. Inzelt concludes that the development of an interactive Triple Helix model is time-consuming. This complements the findings of Balzer and Askonas, showing that a time frame is a very important factor for analysis.

Specific instruments for knowledge transfer applied in Russia are analyzed in the paper by Bychkova, Chernysh, and Popova who explore three measures aimed at the development of industry-academia relations and in the paper of Grasmik who analyzes creation of spin-offs as a mechanism of innovation development at the regional level.

Bychkova et al. look at three different instruments-creation of spin-offs by universities and academy institutes, matching grants for $R \& D$ cooperation between universities and industry, and centers of shared equipment. The authors consider the latter instrument as the most successful one, which is disputable. They draw their conclusions based on interviews mainly conducted in 2012 with a focus on 
top-down state strategies to enforce close positions between academic and industrial partners.

Russia's innovation policy is quite dynamic and therefore measures evaluated in 2012 will look differently from an analysis made in 2013. Thus, matching grants that are criticized in the paper are assessed in other studies as instrument with many positive and long-lasting side effects ${ }^{2}$ despite some bureaucratic obstacles. Then, centers of shared equipment which are considered as success are not seen in such a positive way in some other studies. ${ }^{3}$ The paper presents two models of centers of shared equipment-when they belong to a company and when they are placed on the premises of a university. The model when equipment belongs to a company is especially beneficial because it allows for inviting professors and students to work for the company during a certain period, i.e., intersectoral mobility ensures knowledge transfer. In either model, working together helps to better train students, and, most importantly, to develop trust between researchers at a university and a company. The matter of mutual trust is often explored in analytical works devoted to commercialization of R\&D results. It is an issue in many countries, not only in Russia. But in Russia, the mentality of mistrust and strong disfavor when business venture fails creates additional difficulties for innovative development.

Centers for shared equipment are not the only instrument among those observed by Bychkova et al. that help to develop mutual trust. It is also true for matching grants, especially when a company on a daily basis collaborates with a university on a joint $R \& D$ project. All these instruments are complementary and important for strengthening horizontal science-industry linkages.

One of the three instruments mentioned by Bychkova et al.-creation of spin-offs-is studied in more detail in Grasmik's paper. He looks at this problem from another angle, at a regional level, and sees spin-offs as the basis for networking. The paper touches the same problem of linkages and mutual trust, as well as the development of social capital. Grasmik divides the innovation networks into formal (R\&D joint ventures, strategic alliances, etc.) and informal, based on personal contacts such as friends, family, and previous colleagues. In the Triple Helix model, formal technology transfer mechanisms do not always work effectively at early stages of the innovation system development. As a result, they are replaced by interpersonal communication. The finding of the paper is based on the study of almost 2000 academic spin-offs established until May 2014 in Russia and explores the number of external connections the companies have. The first striking finding is that almost half of spin-offs created by universities have no ties with external companies. At the same time, a regional dimension is more predictable. Calculation of the cumulative index characterizing the intensity of contacts indicates that Moscow and Saint-Petersburg lead with a large advantage over others, followed by Tomsk, Tatarstan, and Novosibirsk. These are well-known regional centers of innovation in Russia and the study confirms their status. Another confirmation of a known phenomenon demonstrated in the paper is the finding that the higher the level of innovation activity in the economy of a region as a whole, and not only in large companies, the higher the motivation to cooperate with local universities. And again, Moscow and St. Petersburg considerably outperform other cities in size and economic parameters, while concentrating most of the country's science base. The overall conclusion underlines the importance of university-industry cooperation which intensity is directly linked to the innovation intensity in the region. 
All five papers touch the issue of social capital in university-industry relations. Knowledge transfer occurs through people, and the quality of linkages depends on skills, experience in cooperation, and other factors. The last paper in the collection is fully devoted to one of the aspects of social capital development-intersectoral mobility of researchers (Dezhina). Intersectoral mobility may acquire different forms: permanent, when a researcher moves from one organization to another for a full-time job; or temporary, as a part-time research work or consulting. Studies of internal mobility show a positive relationship between the level of intersectoral mobility and research productivity, which is the reason for a growing number of countries to introduce measures stimulating such movement of the research workforce. The studies of intersectoral mobility were mainly conducted abroad. They show that in most cases, mobility and research output are positively connected, and both companies and universities benefit from it. In Russia, intersectoral mobility is not widely spread and there is scarce data on this phenomenon. Specific limitations to its study and interpretation are related to the fact that in Russia, in contrast to many other countries, a move from a university or a research institute to an industrial enterprise in many cases means not just a change of place of work but a change of profession, because those entering industry often assume positions of managers, not researchers. In addition, in Russia, there are some specific obstacles to intersectoral mobility of researchers. The practice of inbreeding, when universities fill positions of assistant professors and professors preferentially with their own graduates presents an obstacle to the mobility and also contributes to stagnation in research since the quality of personnel becomes a secondary factor. In Russia, the scale of inbreeding is impressive: about two thirds of teaching staff are working at the universities from which they graduated.

The findings of the paper are derived from the case studies conducted at different types of research organizations and companies in order to assess the current state of intersectoral mobility in Russia and identify government measures that may fit best to promote it. The study showed that the level of intersectoral mobility is low in both directions-from universities and Academy institutes to industry and vice versa. The major reasons for low mobility are not only historical traditions of inbreeding but also low levels of industrial investments in R\&D and thus insignificant interest in knowledge transfer from universities and Academy.

All the papers in the "Russian collection" demonstrate the complexity and nonlinear pace of reforms that have to lead to the Triple Helix model with developed horizontal linkages. Russian innovation system is still a complex of double helices where government is above other actors. Soviet legacy reflected in the mentality of decision makers continues to be among crucial hampering factors.

\section{Endnotes}

${ }^{1}$ See H. Etzkowitz Public Entrepreneur: the trajectory of United States science, technology and industrial policy Science and Public Policy 26 (1): 53-62. 1999.

${ }^{2}$ See, for example, I.Dezhina,Yu.Simachev. Matching Grants for Stimulating Partnerships between Companies and Universities in Innovation Area: Initial Effects in Russia/l Journal of New Economic Association, 2013, №3. pp. 99-122 (in Russian). 
${ }^{3}$ A.Gusev. Perspectives of the Centers of shared equipment: challenges and government policy. http://ckp-rf.ru/upload/iblock/bdb/bdb04b8dff12b109d767f5d0c186dfe0.pdf (in Russian).

\section{Author details}

${ }^{1}$ Group on Science and Industrial Policy, Skolkovo Institute of Science and Technology, Nobelya str., 3, Moscow 143026, Russia. ${ }^{2}$ Triple Helix Association \& International Triple Helix Institute, 1520 Sand Hill Rd, 210, PaloAlto, CA 94304, USA.

Received: 25 October 2016 Accepted: 25 October 2016

Published online: 04 November 2016

Submit your manuscript to a SpringerOpen ${ }^{\circ}$ journal and benefit from:

- Convenient online submission

- Rigorous peer review

- Immediate publication on acceptance

- Open access: articles freely available online

- High visibility within the field

- Retaining the copyright to your article 